\title{
Postprandial oxidative stress in response to dextrose and lipid meals of differing size
}

\author{
Richard J Bloomer, Mohammad M Kabir, Kate E Marshall, Robert E Canale, Tyler M Farney
}

\begin{abstract}
We have recently noted that ingestion of dietary lipid (in the form of heavy whipping cream) leads to greater oxidative stress than dietary carbohydrate (in the form of dextrose), when consumed in isocaloric amounts.
\end{abstract}

Objective: In the present investigation we attempted to replicate our work and also to determine the oxidative stress response to dextrose and lipid meals of two different kilocalorie (kcal) amounts.

Design: Nine young (22 \pm 2 years), healthy men consumed in a random order, cross-over design one of four meals/drinks: dextrose at $75 \mathrm{~g}$ (300 kcals), dextrose at $150 \mathrm{~g}$ (600 kcals), lipid at $33 \mathrm{~g}$ (300 kcals), lipid at $66 \mathrm{~g}$ (600 kcals). Blood samples were collected Pre meal, and at $30 \mathrm{~min}, 60 \mathrm{~min}, 120 \mathrm{~min}$, and $180 \mathrm{~min}$ post meal. Samples were assayed for glucose, triglycerides (TAG), malondialdehyde (MDA), and hydrogen peroxide $\left(\mathrm{H}_{2} \mathrm{O}_{2}\right)$. Area under the curve (AUC) was calculated for each variable, and a $4 \times 5$ ANOVA was utilized to further analyze data.

Results: A meal $\times$ time effect $(p=0.0002)$ and a time effect was noted for glucose $(p<0.0001 ; 30 \mathrm{~min}>$ Pre, $1 \mathrm{hr}$, $2 \mathrm{hr}$, and $3 \mathrm{hr}$ ). The dextrose meals primarily contributed to this time effect. No other effects were noted for glucose $(p>0.05)$. A meal effect was noted for TAG $(p=0.01 ; 66 \mathrm{~g}$ lipid meal $>75 \mathrm{~g}$ and $150 \mathrm{~g}$ dextrose meals). No other effects were noted for TAG ( $p>0.05$ ). An AUC effect was noted for MDA ( $p=0.04 ; 66 \mathrm{~g}$ lipid meal $>75$ $\mathrm{g}$ and $150 \mathrm{~g}$ dextrose meals). A meal $\times$ time effect $(p=0.02)$ and a meal effect was noted for MDA $(p=0.004 ; 66$ $\mathrm{g}$ lipid meal $>75 \mathrm{~g}$ and $150 \mathrm{~g}$ dextrose meals). No time effect was noted for MDA ( $p=0.72)$. An AUC effect was noted for $\mathrm{H}_{2} \mathrm{O}_{2}$ ( $p=0.0001 ; 66 \mathrm{~g}$ lipid meal $>33 \mathrm{~g}$ lipid meal and $75 \mathrm{~g}$ and $150 \mathrm{~g}$ dextrose meals). A meal $\times$ time effect ( $p=0.0002)$, a meal effect ( $p<0.0001 ; 66 \mathrm{~g}$ lipid meal $>33 \mathrm{~g}$ lipid meal and $75 \mathrm{~g}$ and $150 \mathrm{~g}$ dextrose meals), and a time effect was noted for $\mathrm{H}_{2} \mathrm{O}_{2}$ ( $p<0.0001 ; 2 \mathrm{hr}>$ Pre, $30 \mathrm{~min}$, and $1 \mathrm{hr} ; 3 \mathrm{hr}>$ Pre). The time effect for $\mathrm{H}_{2} \mathrm{O}_{2}$ was primarily influenced by the $66 \mathrm{~g}$ lipid meal.

Conclusions: These data indicate that 1) minimal oxidative stress is observed following ingestion of dextrose loads of either $75 \mathrm{~g}$ or $150 \mathrm{~g}$, or a lipid load of $33 \mathrm{~g}$ and 2) lipid ingestion at $66 \mathrm{~g}$ leads to greater oxidative stress than lipid at $33 \mathrm{~g}$ or dextrose at either $75 \mathrm{~g}$ or $150 \mathrm{~g}$. Hence, in a sample of young and healthy men, only $66 \mathrm{~g}$ of lipid (taken in the form of heavy whipping cream) leads to a significant increase in blood oxidative stress, as measured by $\mathrm{MDA}$ and $\mathrm{H}_{2} \mathrm{O}_{2}$.

\section{Introduction}

The process of normal cellular metabolism leads to the production of reactive oxygen species (ROS), the majority of which are inactivated by endogenous and exogenous antioxidants [1]. The balance between ROS production and antioxidant defense determines the intracellular redox environment, which is responsible for the initiation/regulation of multiple physiological processes within living systems, controlling functions such

\footnotetext{
* Correspondence: rbloomer@memphis.edu

Cardiorespiratory/Metabolic Laboratory, Department of Health and Sport Sciences, University of Memphis, Memphis, TN, USA
}

as cell signaling, DNA and RNA synthesis, protein synthesis, enzyme activation, and apoptosis $[2,3]$.

In general, a low-grade production of ROS (i.e., more reducing conditions) is associated with enhanced health; whereas, excessive ROS production and a chronic oxidative shift in the redox environment has been implicated in a wide variety of pathological conditions [4]. This later scenario is commonly referred to as oxidative stress [1] and occurs when ROS production is increased and/ or antioxidant defenses are decreased. This is well described under conditions of increased environment stress [1] and physical stress [5,6], as well as following ingestion of high carbohydrate and high fat meals in 
which increased substrate metabolism occurs [7]. These and other ROS-generating stimuli can result in oxidative damage to nucleic acids, lipids, and proteins, which has the potential to contribute to the development of human disease [8]. In fact, oxidative stress is suggested to play a primary or secondary role in the pathophysiological mechanisms of multiple acute and chronic human illnesses/diseases [8].

In relation to the ingestion of food, oxidative stress has been reported to occur during the minutes to hours following intake. This "postprandial oxidative stress" is likely a result of both a dramatic increase in ROS production, coupled with a decrease in antioxidant defense (commonly measured in blood samples of human participants) [7]. Following ingestion of carbohydrate and lipid rich meals, an acute state of hyperglycemia/hypertriglyceridemia may result, which is evidenced by an increase in circulating blood glucose, free fatty acids, and triglycerides [9]. This excessive influx of substrate, either within the circulation and/or peripheral tissues, appears to be associated with an increased leakage of electrons from within the mitochondrial respiratory chain, thereby resulting in accelerated superoxide generation [10-12]. Superoxide (possibly working through the activation of nuclear transcription factor- $\kappa \beta$ [13]) appears to stimulate a harmful biochemical cascade throughout the circulation, which induces inflammation, endothelial dysfunction, hypercoagulability, and sympathetic hyperactivity, all of which may promote further ROS generation and oxidative damage [9].

The postprandial production of ROS appears highly correlated to both the glucose [14] and the TAG response to feeding [15-18]. This is evident by reported increases in blood biomarkers of oxidative stress during the postprandial period. Multiple studies have used either independent administration of a lipid [16-25] or carbohydrate rich meal $[22,26-34]$ to induce oxidative stress.

In terms of comparisons between carbohydrate and lipid meals, we have recently noted that ingestion of dietary lipid (in the form of heavy whipping cream) leads to significantly greater oxidative stress than dietary carbohydrate (in the form of dextrose), when these are consumed in isocaloric amounts [18]. Our subsequent work indicates that carbohydrate in the form of either dextrose or maltodextrin does not result in a significant amount oxidative stress, even when consumed at an amount equal to $2.25 \mathrm{~g}$ per $\mathrm{kg}$ body mass by healthy men [35]. Together, these findings provide evidence to support the notion that high fat diets may be more detrimental to overall health than high carbohydrate diets (at least with regards to young, otherwise healthy men). However, it remains unknown what the effect of meals that differ in kcals have on postprandial oxidative stress.
While it is logical to assume that higher kcal meals of the same nutrient will result in greater oxidative stress, to our knowledge, no study to date has determined this. It is possible that a ceiling effect occurs for ROS production and subsequent oxidative stress, in that consumption of nutrients above a certain amount may not lead to further ROS production. To address this question, the present study was designed to 1 ) replicate our initial work demonstrating a greater oxidative stress for lipid compared to isocaloric carbohydrate feedings, and to 2) determine the effect of carbohydrate and lipid meals of two different caloric contents on postprandial oxidative stress. We hypothesized that the lipid meals would result in greater oxidative stress as compared to the dextrose meals and that the degree of oxidative stress would be dependent on meal size (larger meals = greater oxidative stress).

\section{Methods}

\section{Subjects}

Ten young, healthy men were recruited from the University of Memphis and surrounding community and completed all aspects of this study. Sample size was chosen based on our prior work and the work of others focused on postprandial oxidative stress using similar outcome variables. All subjects were non-smokers, of normal weight, normolipidemic (fasting triglycerides $<200 \mathrm{mg} \cdot \mathrm{dL}^{-1}$ ), non-diabetic (fasting glucose $<126$ $\left.\mathrm{mg} \cdot \mathrm{dL}^{-1}\right)$, not regularly using antioxidant supplements or drugs, and did not have diagnosed cardiovascular or metabolic disorders. It should be noted that only nine subjects successfully completed all meal testing. Subject descriptive characteristics are presented in Table 1.

Health history, drug and dietary supplement usage, and physical activity questionnaires were completed by subjects to determine eligibility. Prior to participation, each subject was informed of the procedures, potential

\section{Table 1 Characteristics of 9 men}

\begin{tabular}{ll}
\hline Variable & Value \\
\hline Age $(\mathrm{yrs})$ & $22 \pm 2$ \\
Height $(\mathrm{cm})$ & $181 \pm 8$ \\
Weight $(\mathrm{kg})$ & $82 \pm 12$ \\
BMI $\left(\mathrm{kg} \cdot \mathrm{m}^{-2}\right)$ & $25 \pm 4$ \\
Body fat $(\%)$ & $19 \pm 7$ \\
Waist $(\mathrm{cm})$ & $84 \pm 9$ \\
Hip $(\mathrm{cm})$ & $103 \pm 6$ \\
Resting heart rate $(\mathrm{bpm})$ & $68 \pm 10$ \\
Resting SBP $(\mathrm{mmHg})$ & $117 \pm 6$ \\
Resting DBP $(\mathrm{mmHg})$ & $66 \pm 9$ \\
Fasting glucose $\left(\mathrm{mg} \cdot \mathrm{dL}^{-1}\right)$ & $102 \pm 14$ \\
Fasting triglycerides $\left(\mathrm{mg}^{-1} \mathrm{dL}^{-1}\right)$ & $90 \pm 50$ \\
\hline
\end{tabular}

Data are mean $\pm S D$ 
risks, and the benefits associated with the study. This was done through both verbal and written form in accordance with the approved procedures of the University Institutional Review Board for Human Subjects Research. Subjects signed an informed consent form (approval \# H10-09) prior to be being admitted as a subject.

\section{Subject Screening (initial laboratory visit)}

During the initial visit to the laboratory, subjects completed the informed consent form, health form, and physical activity questionnaire. The height, weight, and body composition (via 7 site skinfold assessment) of each subject was measured using a stadiometer, digital scale, and Lange skin fold calipers, respectively. Heart rate (via palpation) and blood pressure (via auscultation) were recorded following a 10 minute period of quiet rest. An explanation of dietary data recording was provided, along with data collection forms.

\section{Meal Testing}

All subjects who met study criteria reported to the laboratory in the morning following a 10-hour overnight fast. Subjects rested for 10 minutes and then a pre-meal blood sample was collected. On four different days, in random order cross-over design, and separated by 3-7 days, subjects consumed one of four meals: dextrose at 75 grams (300 calories), dextrose at 150 grams (600 calories), lipid at 33 grams (300 calories), lipid at 66 grams (600 calories). The dextrose was in powder form (NOW Foods, Bloomingdale, IL; 100\% carbohydrate kcal; 100\% sugar) and the lipid consisted of heavy whipping cream (standard dairy grade; $100 \%$ fat kcal; 60\% saturated fat, $30 \%$ monounsaturated fat, $10 \%$ polyunsaturated fat). The $300 \mathrm{kcal}$ drinks contained a total of $350 \mathrm{~mL}$ of fluid and the $600 \mathrm{kcal}$ drinks contained a total of $700 \mathrm{~mL}$ of fluid. The amount of dextrose powder and whipping cream was weighed (laboratory grade balance) and measured prior to the mixing of each drink. The volume of water added to each drink (in order to bring the total volume to $350 \mathrm{~mL}$ or $700 \mathrm{~mL}$ ) was measured in a graduated cylinder. All portions were mixed in a blender. Subjects were given 10 minutes to consume the assigned drink.

The postprandial observation period lasted three hours, during which time four additional blood samples were collected ( $30 \mathrm{~min}, 60 \mathrm{~min}, 120 \mathrm{~min}$, and $180 \mathrm{~min}$ ). We have noted in our previous work that in healthy men, the peak oxidative stress response occurs between $2-4$ hours following ingestion of a lipid meal $[17,18,36]$. Therefore, we believed that ceasing the observation period at 3 hours post feeding was justified. Subjects remained in the laboratory during this period (or in close proximity) and expended as little energy as possible. No additional meals or calorie containing beverages were allowed during this period. Water was allowed ad libitum during the first test day and matched for all subsequent test days. These procedures are similar to those we have used in several recent investigations [16-18,36-39].

\section{Blood Sampling and Biochemistry}

Venous blood samples $(\sim 15 \mathrm{~mL})$ were taken from subjects' forearm via needle and Vacutainer by a trained phlebotomist. Following collection, blood samples were processed accordingly, and the plasma/serum was immediately stored at $-70^{\circ} \mathrm{C}$ until analyzed. All blood samples were assayed for the following variables: glucose, triglycerides (TAG), malondialdehyde (MDA), and hydrogen peroxide $\left(\mathrm{H}_{2} \mathrm{O}_{2}\right)$. We have recently studied these same variables in response to isocaloric dextrose and lipid meals (albeit only one size, as opposed to two different sizes in the present design). Therefore, we wanted to have similarity in our measures for the current study.

Assays for serum glucose and TAG were performed following standard enzymatic procedures as described by the reagent manufacturer (Thermo Electron Clinical Chemistry). Standard curves for all assays were developed for determination of unknown samples. MDA was analyzed in plasma using a commercially available colorimetric assay (Northwest Life Science Specialties, Vancouver, WA), using previously described methods [40]. $\mathrm{H}_{2} \mathrm{O}_{2}$ was analyzed in plasma using the Amplex Red reagent method as described by the manufacturer (Molecular Probes, Invitrogen Detection Technologies, Eugene, OR). In the reaction mixture, hydrogen peroxide, in the presence of horseradish peroxidase, reacts with Amplex Red reagent to generate the red-fluorescence oxidation product, resorufin. All assays were performed in duplicate on first thaw. These are commonly performed within our laboratory and the coefficient of variation for all measures is $\leq 7 \%$.

\section{Dietary Records}

Subjects were instructed to maintain their normal diet, and to record their food and beverage intake during the 24 hour period prior to each test day. Subjects were asked to consume similar food choices and quantities during the 24 hours prior to each test day. Nutritional records were analyzed for total kcals, protein, carbohydrate, fat, vitamin C, vitamin E, and vitamin A (Food Processor SQL, version 9.9, ESHA Research, Salem, OR). Subjects were asked to maintain their normal physical activity habits during the study period but to avoid strenuous exercise during the 24 hours immediately preceding the test days, since such activity may have impacted the chosen biomarkers, as reported previously $[41,42]$. 


\section{Statistical Analysis}

For each biomarker, the area under the curve (AUC) was calculated using the trapezoidal method as described in detail by Pruessner et al. [43]. In addition, biochemical variables were analyzed using a 4 (meal) $\times$ 5 (time) repeated measures analysis of variance (ANOVA). Significant interactions and main effects were further analyzed using Tukey's post hoc tests. Dietary variables were analyzed using a one-way ANOVA. Pairwise correlations were made between all biomarkers using AUC data. All analyses were performed using JMP statistical software (version 4.0.3, SAS Institute, Cary, NC). Statistical significance was set at $\mathrm{P} \leq 0.05$. The data are presented as mean \pm SEM, except for subject descriptive characteristics which are presented as mean $\pm \mathrm{SD}$.

\section{Results}

As indicated earlier, although 10 subjects were enrolled in the study, only nine subjects successfully completed all meal testing. One subject decided not to complete the testing protocol due to loss of interest. Therefore, data are only presented for nine subjects. No statistically significant differences were noted for kilocalories $(\mathrm{p}=0.34)$, protein grams $(p=0.87)$, carbohydrate grams $(p=0.50)$, fat grams $(\mathrm{p}=0.53)$, vitamin $\mathrm{C}(\mathrm{p}=0.76)$, vitamin $\mathrm{E}(\mathrm{p}=0.85)$, or vitamin A ( $\mathrm{p}=0.73)$. Data are presented in Table 2.

For blood glucose, no AUC effect was noted ( $p=0.44$ ). No meal effect was noted ( $p=0.13)$, although both a meal $x$ time effect $(\mathrm{p}=0.0002)$ and a time effect was noted $(\mathrm{p}<$ 0.0001 ), with $30 \mathrm{~min}$ greater than Pre, $1 \mathrm{hr}, 2 \mathrm{hr}$, and $3 \mathrm{hr}$ $(\mathrm{p}<0.05)$. As expected, the glucose meals contributed most to this time effect. Data are presented in Figure 1.

For blood TAG, no AUC effect was noted ( $p=0.26)$. No meal $\times$ time effect $(p=0.27)$ or time effect was noted $(\mathrm{p}=0.63)$. However, a meal effect was noted $(\mathrm{p}=$ 0.01 ), with the $66 \mathrm{~g}$ lipid meal greater than the $75 \mathrm{~g}$ and $150 \mathrm{~g}$ dextrose meals $(\mathrm{p}<0.05)$. Data are presented in Figure 2.

Table 2 Dietary data of $\mathbf{9}$ men during the $\mathbf{2 4}$ hours
before intake of a dextrose or lipid meal
\begin{tabular}{lllll}
\hline Variable & Dextrose & Dextrose & Lipid & Lipid \\
& $\mathbf{7 5 ~ g}$ & $\mathbf{1 5 0} \mathbf{~ g}$ & $\mathbf{3 3} \mathbf{~ g}$ & $\mathbf{6 6 ~ g}$ \\
\hline Kilocalories & $2023 \pm 237$ & $2354 \pm 242$ & $1983 \pm 206$ & $1789 \pm 181$ \\
Protein (g) & $92 \pm 11$ & $102 \pm 9$ & $95 \pm 13$ & $88 \pm 16$ \\
Carbohydrate (g) & $261 \pm 39$ & $315 \pm 41$ & $248 \pm 31$ & $247 \pm 33$ \\
Fat (g) & $72 \pm 11$ & $81 \pm 12$ & $72 \pm 13$ & $57 \pm 9$ \\
Vitamin C (mg) & $64 \pm 26$ & $47 \pm 11$ & $40 \pm 7$ & $51 \pm 13$ \\
Vitamin E (mg) & $4 \pm 2$ & $4 \pm 1$ & $3 \pm 1$ & $3 \pm 1$ \\
Vitamin A (RE) & $267 \pm 82$ & $374 \pm 110$ & $228 \pm 113$ & $236 \pm 102$
\end{tabular}

Data are mean \pm SEM.

No statistically significant differences noted for kilocalories $(p=0.34)$, protein $(p=0.87)$, carbohydrate $(p=0.50)$, fat $(p=0.53)$, vitamin $C(p=0.76)$, vitamin $E(p=0.85)$, or vitamin $A(p=0.73)$.
For blood MDA, an AUC effect was noted ( $\mathrm{p}=0.04$ ), with the $66 \mathrm{~g}$ lipid meal greater than the $75 \mathrm{~g}$ and $150 \mathrm{~g}$ dextrose meals $(\mathrm{p}<0.05)$. A meal $\times$ time effect $(\mathrm{p}=$ $0.02)$ and a meal effect was noted $(\mathrm{p}=0.004)$, with the $66 \mathrm{~g}$ lipid meal greater than the $75 \mathrm{~g}$ and $150 \mathrm{~g}$ dextrose meals $(\mathrm{p}<0.05)$. However, no time effect was noted $(\mathrm{p}=0.72)$. Data are presented in Figure 3.

For blood $\mathrm{H}_{2} \mathrm{O}_{2}$, an AUC effect was noted ( $\mathrm{p}=$ $0.0001)$, with the $66 \mathrm{~g}$ lipid meal greater than the $33 \mathrm{~g}$ lipid meal and the $75 \mathrm{~g}$ and $150 \mathrm{~g}$ dextrose meals $(\mathrm{p}<$ $0.05)$. A meal $\times$ time effect $(p=0.0002)$, a meal effect $(\mathrm{p}<0.0001)$, and a time effect was noted $(\mathrm{p}<0.0001)$. Regarding the meal effect, the $66 \mathrm{~g}$ lipid meal was greater than the $33 \mathrm{~g}$ lipid meal and the $75 \mathrm{~g}$ and $150 \mathrm{~g}$ dextrose meals $(\mathrm{p}<0.05)$. With regards to the time effect, $2 \mathrm{hr}$ was greater than Pre, $30 \mathrm{~min}$, and $1 \mathrm{hr} ; 3 \mathrm{hr}$ was greater than Pre $(p<0.05)$. Data are presented in Figure 4.

When considering all four meals combined and using values generated using the AUC analysis, significant positive correlations were noted between many biochemical variables $(\mathrm{p}<0.05)$. A correlation matrix is provided in Table 3.

\section{Discussion}

We noted two main findings from the present investigation. First, minimal oxidative stress is observed following ingestion of dextrose loads of either $75 \mathrm{~g}$ or $150 \mathrm{~g}$, or a lipid load of $33 \mathrm{~g}$ (Figure 3 and Figure 4). Considering these data, it is clear that even with consumption of a very high load of simple sugar (150 g dextrose), minimal blood oxidative stress occurs (at least as measured using the indirect markers of MDA and $\mathrm{H}_{2} \mathrm{O}_{2}$ ). This is true despite the transient increase in blood glucose following ingestion of both the $75 \mathrm{~g}$ and $150 \mathrm{~g}$ dextrose meals (Figure 1). Furthermore, we noted only a small increase in oxidative stress (and TAG) in response to the $33 \mathrm{~g}$ lipid meal, indicating that a relatively small lipid load is well tolerated by young, healthy men. Considered collectively, ingestion of simple sugar or moderate amounts of dietary fat (33 g) may not pose any significant health concerns in young, healthy individuals, at least as measured in an acute state. Of course, regular and longterm consumption of such nutrients may result in other potential problems which may not be directly related to postprandial oxidative stress (e.g., weight gain, impaired insulin sensitivity).

Of course, it is possible that an increase in oxidative stress may have been noted following intake of these meals if other biomarkers aside from MDA and $\mathrm{H}_{2} \mathrm{O}_{2}$ were included. It should be noted that besides our previous work, both MDA and $\mathrm{H}_{2} \mathrm{O}_{2}$ have been used by other investigators in previous studies of postprandial oxidative stress: MDA $[20,33,44]$ and $\mathrm{H}_{2} \mathrm{O}_{2}[31,45]$. 

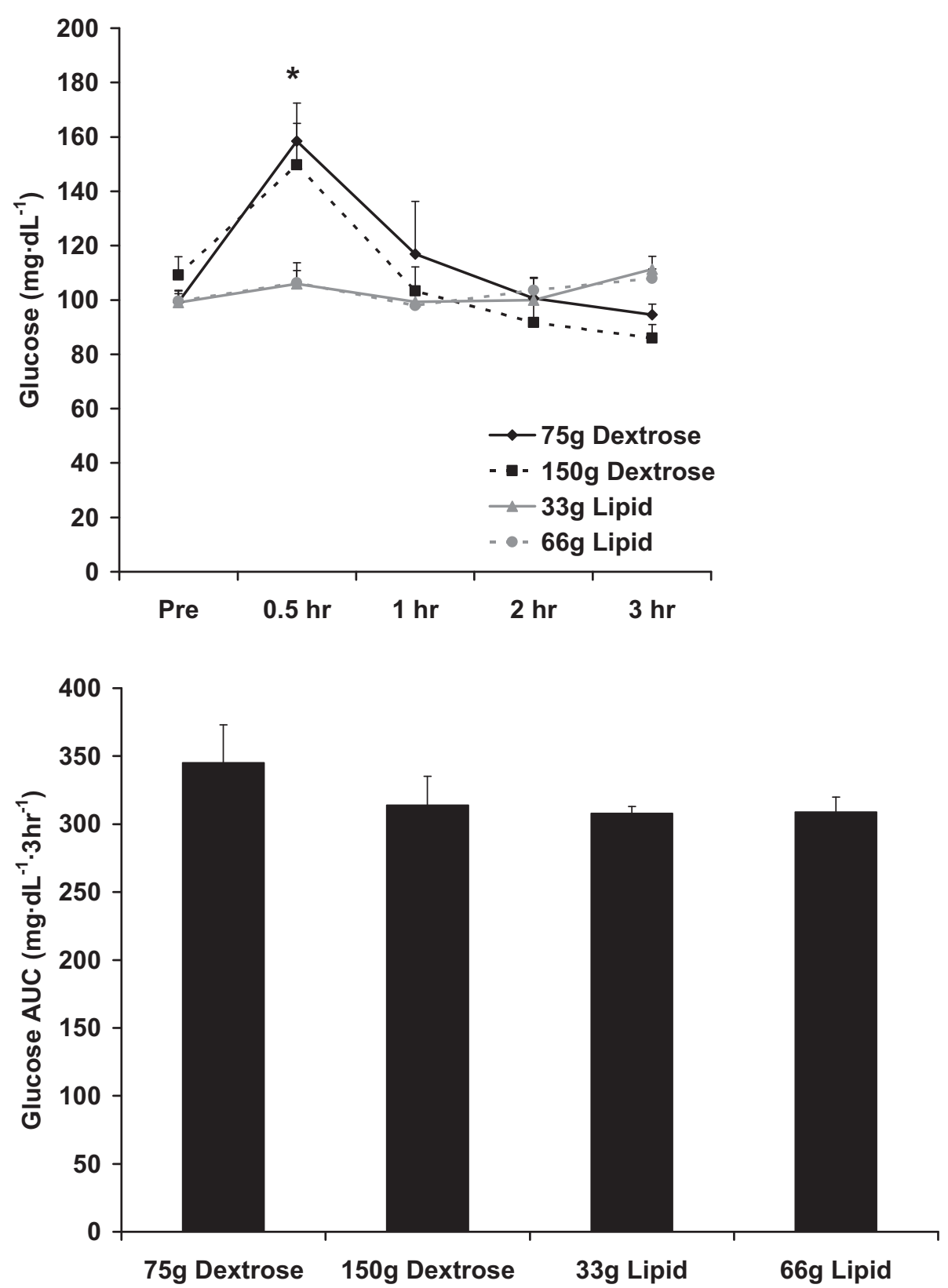

Figure 1 Blood glucose before and following the consumption of a dextrose or lipid meal in young healthy men. Data are mean \pm SEM. Meal effect $(p=0.13)$. ${ }^{*}$ Time effect $(p<0.0001) ; 0.5 \mathrm{hr}>$ Pre, $1 \mathrm{hr}, 2 \mathrm{hr}$, and $3 \mathrm{hr}$. Meal $\times$ Time effect $(p=0.0002)$. AUC effect $(p=0.44)$.

A limitation of the present study is the omission of other commonly assessed oxidative stress biomarkers such as protein carbonyls, glutathione (oxidized and reduced), and nitrotyrosine, as well as other specific markers of lipid peroxidation such as $\mathrm{F}_{2}$-isoprostanes [8]. Future work may consider the inclusion of these additional assays in an attempt to better characterize the system following ingestion of both dextrose and lipid meals.
In addition to the above, other limitations of this work should be noted. First, it is important to mention that as with most studies in this area of investigation, we only measured blood oxidative stress in the present study. Therefore, we cannot assume that oxidative stress did not occur in tissue aside from blood. Second, it should be mentioned that the biomarkers utilized in the present investigation are considered indirect indicators of oxidative stress. Indirect assessment of oxidative stress involves the measurement of the more stable molecular 

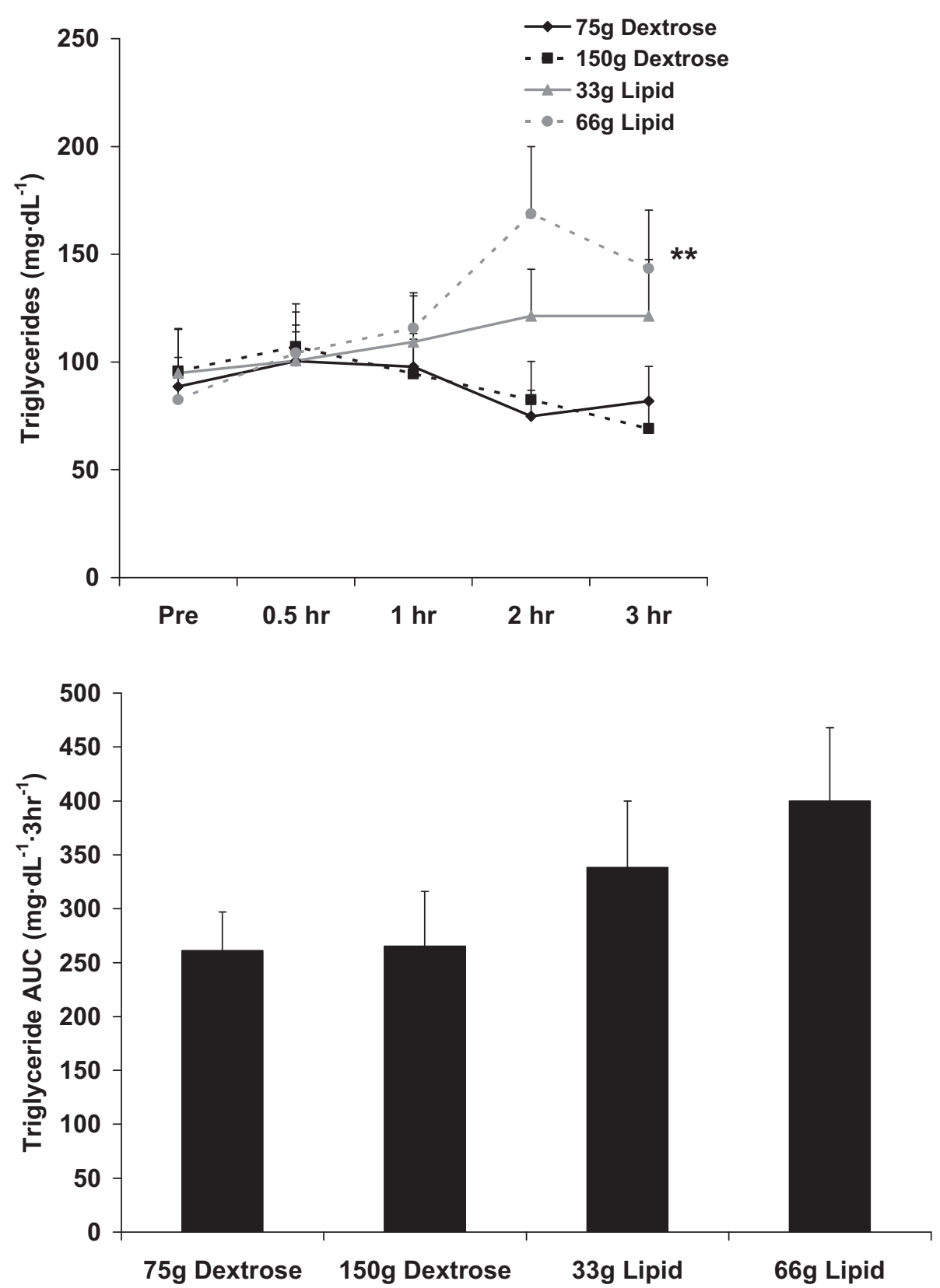

Figure 2 Blood triglycerides before and following the consumption of a dextrose or lipid meal in young healthy men. Data are mean \pm SEM. ** Meal effect $(p=0.01)$; $66 \mathrm{~g}$ Lipid $>75 \mathrm{~g}$ Dextrose and $150 \mathrm{~g}$ Dextrose. Time effect $(p=0.63)$. Meal $\times$ Time effect $(p=0.27)$. AUC effect $(p$ $=0.26$ ).

products formed via the reaction of ROS with certain biomolecules [8], as opposed to the direct quantification of ROS. This method is most commonly used throughout the literature, as direct measurement of radical production (via electron spin resonance spectroscopy) is very costly and labor intensive. Despite the regular use of indirect techniques, this could still be considered a limitation of the present investigation. Third, although we noted no differences in dietary intake over the 24 hour period prior to each test day, it is possible that differences in other variables not included in our analysis (e.g., specific antioxidants) could have impacted our findings. Moreover, differences in dietary intake during the week, rather than the day, preceding each test day may have influenced our findings. Fourth, our sample size of nine men, although similar to many other studies in the literature, is relatively small and may have impaired our ability to note statistical significance in 

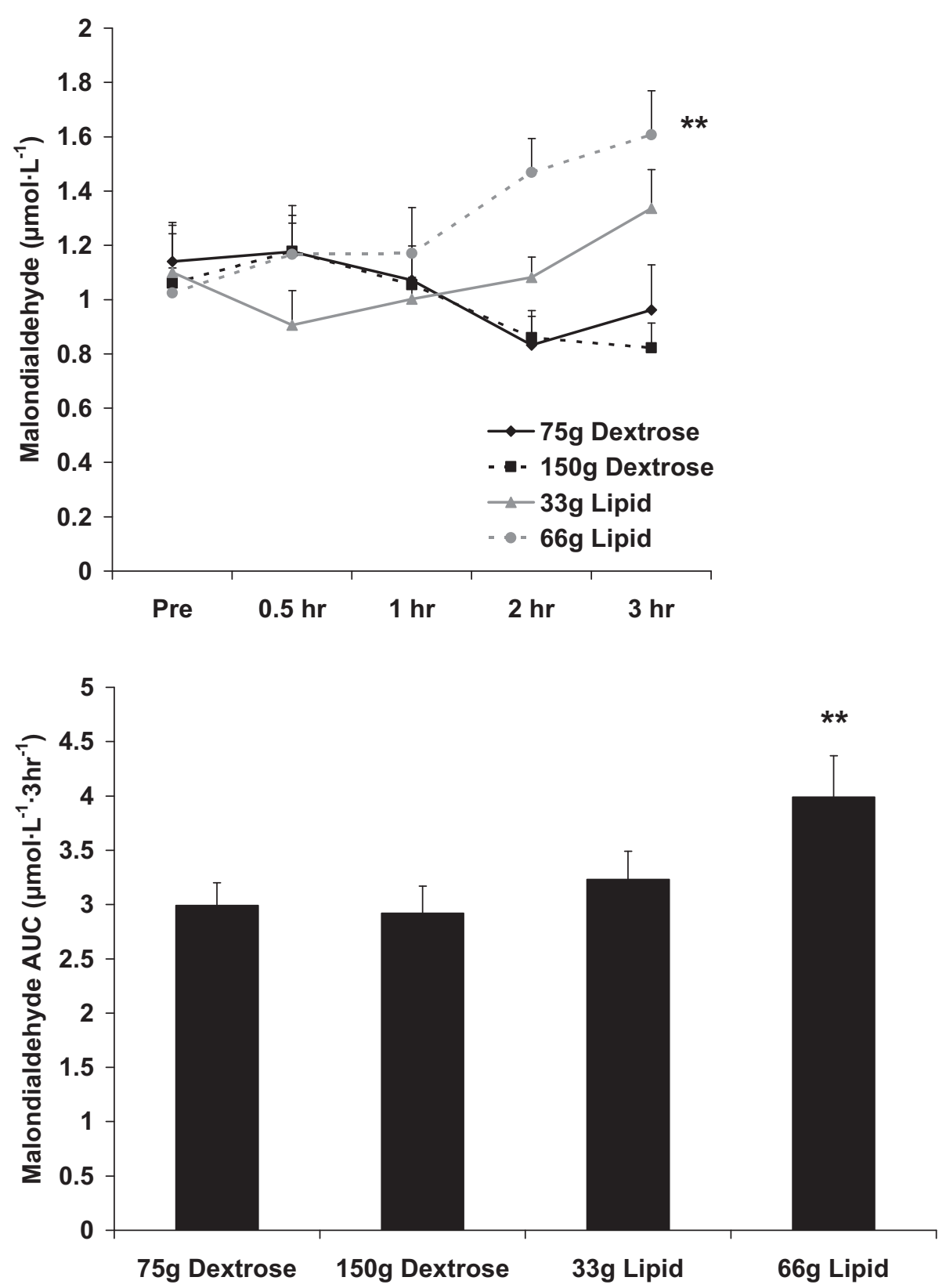

Figure 3 Blood malondialdehyde before and following the consumption of a dextrose or lipid meal in young healthy men. Data are mean \pm SEM. ${ }^{* *}$ Meal effect $(p=0.004) ; 66 \mathrm{~g}$ Lipid $>75 \mathrm{~g}$ Dextrose and $150 \mathrm{~g}$ Dextrose. Time effect $(p=0.72)$. Meal $\times$ Time effect $(p=0.02)$.

**AUC effect $(p=0.04) ; 66 \mathrm{~g}$ Lipid $>75 \mathrm{~g}$ Dextrose and $150 \mathrm{~g}$ Dextrose.

some instances. Future studies may consider the inclusion of a larger subject sample. Fifth and not necessarily a limitation, our subjects were young and healthy, with most involved in regular physical activity programs. It is possible that older individuals and/or those with known metabolic disorders (e.g., obesity, diabetes) may have responded differently to the meals. Further work should consider the above prior to attempting to generalize results to populations other than young and healthy men, as doing so may be problematic.

Second with regards to our main findings, lipid ingestion at $66 \mathrm{~g}$ leads to greater oxidative stress than lipid at $33 \mathrm{~g}$ or dextrose at either $75 \mathrm{~g}$ or $150 \mathrm{~g}$. These data 1) confirm the results from our prior work in which we noted that ingestion of dietary lipid (heavy whipping cream) leads to greater oxidative stress than ingestion of 

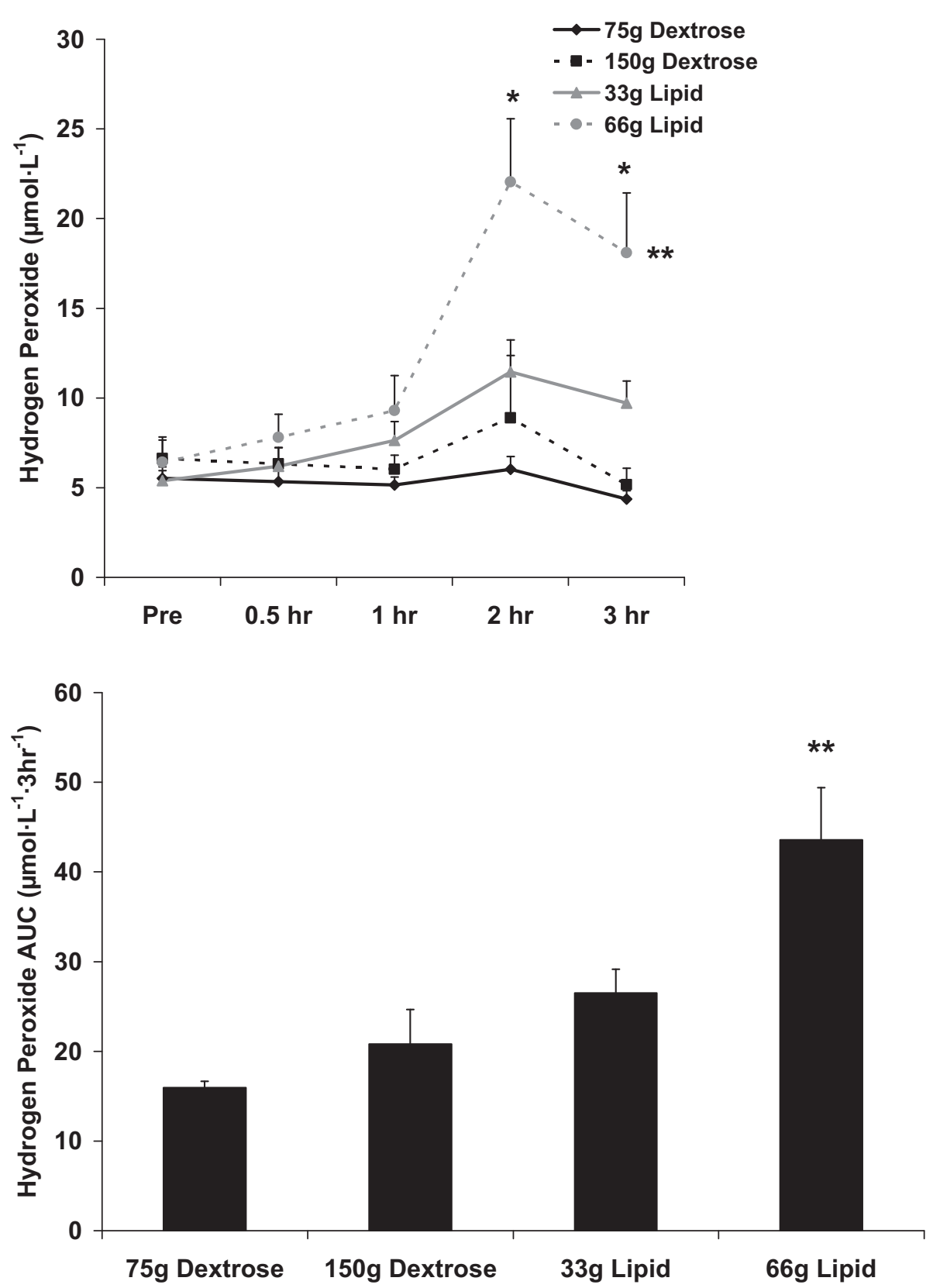

Figure 4 Blood hydrogen peroxide before and following the consumption of a dextrose or lipid meal in young healthy men. Data are mean \pm SEM. ${ }^{* *}$ Meal effect $(p<0.0001) ; 66 \mathrm{~g}$ Lipid $>33 \mathrm{~g}$ Lipid, $75 \mathrm{~g}$ Dextrose, and $150 \mathrm{~g}$ Dextrose. ${ }^{*}$ Time effect $(p<0.0001) ; 2 \mathrm{hr}>$ Pre, 0.5 hr, and 1 hr; 3 hr $>$ Pre. Meal $\times$ Time effect $(p=0.0002)$. ${ }^{* *}$ AUC effect $(p=0.0001) ; 66 \mathrm{~g}$ Lipid $>33 \mathrm{~g}$ Lipid, $75 \mathrm{~g}$ Dextrose, and $150 \mathrm{~g}$ Dextrose.

Table 3 Correlation matrix using AUC values for biochemical variables collapsed over all meals.

\begin{tabular}{|c|c|c|c|c|}
\hline & Glucose & Triglyceride & Malondialdehyde & Hydrogen Peroxide \\
\hline Glucose & & $\begin{array}{c}0.18 \\
p=0.30\end{array}$ & $\begin{array}{c}0.03 \\
p=0.86\end{array}$ & $\begin{array}{c}0.17 \\
p=0.35\end{array}$ \\
\hline Triglyceride & $\begin{array}{c}0.18 \\
p=0.30\end{array}$ & & $\begin{array}{c}0.70 \\
p<0.0001\end{array}$ & $\begin{array}{c}0.53 \\
P=0.001\end{array}$ \\
\hline Malondialdehyde & $\begin{array}{c}0.03 \\
p=0.86\end{array}$ & $\begin{array}{c}0.70 \\
p<0.0001\end{array}$ & & $\begin{array}{c}0.54 \\
P=0.0008\end{array}$ \\
\hline Hydrogen Peroxide & $\begin{array}{c}0.17 \\
p=0.35\end{array}$ & $\begin{array}{c}0.53 \\
P=0.001\end{array}$ & $\begin{array}{c}0.54 \\
P=0.0008\end{array}$ & \\
\hline
\end{tabular}


dietary carbohydrate (dextrose), when consumed in isocaloric amounts [18] and 2) confirm our hypothesis that the magnitude of oxidative stress is dependent on the amount of lipid consumed (66 g > $33 \mathrm{~g}$ ). However, meal size was not a factor when considering dextrose, as neither the $75 \mathrm{~g}$ nor the $150 \mathrm{~g}$ dextrose meal resulted in a significant amount of oxidative stress. Again, it is likely that our specific subject sample influenced these findings for both macronutrients, as differing results may have been observed if we included older, overweight, and/or diabetic subjects. Regardless, it is important to note that even in young, healthy subjects who appear to tolerate well, a moderate dose of lipid, as well as moderate to high doses of simple sugar, a high dose of lipid is detrimental in terms of elevating postprandial oxidative stress. Considering the relationship between oxidative stress and the development and progression of human disease [8], routine ingestion of meals rich in saturated fat (consumed as heavy whipping cream in the current study) should be strongly discouraged.

In relation to $\mathrm{H}_{2} \mathrm{O}_{2}$ production, and subsequent formation of MDA, a greater postprandial increase following the lipid meal would be expected based on the commonly accepted mechanisms underlying the regulation of postprandial superoxide production [46]. Considering that superoxide is produced within the mitochondria during substrate oxidation, and because a greater relative supply of electrons downstream to complex I would be expected to be produced as a consequence of accelerated betaoxidation (via $\mathrm{FADH}_{2}$ donation to electron transferring flavoprotein-coenzyme Q oxidoreductase [47]), it follows that the lipid meals (which yield significantly more $\mathrm{FADH}_{2}$ than do carbohydrate) would promote greater $\mathrm{H}_{2} \mathrm{O}_{2}$ production compared to the dextrose meals. These findings are in agreement with our work [18] and the work of others $[15,32,48]$, noting greater postprandial oxidative stress following lipid rich meals compared to carbohydrate rich meals. A detailed review pertaining to the role of ROS following ingestion of lipid meals is beyond the scope of this discussion, but can be found in our recent review on this topic [49].

Our results for the dextrose meals parallel some previous findings of minimal increase in oxidative stress when assessed using young, healthy subjects $[18,26,29,35,44]$, but refute other work which has shown an increase in various markers of oxidative stress following a $75 \mathrm{~g}$ oral glucose tolerance test [22,26-31]. However, the majority of investigations reporting increased oxidative stress following carbohydrate meals include diabetics as subjects [22,26-30,32-34]. It follows that oxidative stress may be elevated in such individuals, as exacerbations in postprandial oxidative stress have been associated with an insulin resistant state $[22,26,29,30]$. As stated above, caution should be taken when attempting to extrapolate our present findings to populations other than young, healthy men.

Related to the lipid meals, in particular the $66 \mathrm{~g}$ lipid meal, the TAG response to feeding was greater than that of the dextrose meals (Figure 2). Based on the noted correlations between TAG, MDA, and $\mathrm{H}_{2} \mathrm{O}_{2}$ (Table 3), it follows that the lipid meals (in particular the $66 \mathrm{~g}$ lipid meal) resulted in a greater oxidative stress as compared to the dextrose meals. However, it should first be noted that the increase in $\mathrm{H}_{2} \mathrm{O}_{2}$ and MDA, although thought to be influenced mainly by the TAG response to feeding, could have been affected by other non-related factors (e.g., ex vivo oxidation during the assay procedures). Second, it should be understood that the magnitude and time course of response for TAG, MDA, and $\mathrm{H}_{2} \mathrm{O}_{2}$ does not exactly parallel one another, as can be observed in Figures 2, 3, and 4. It is possible that the early increase in blood TAG (which seems to peak by 2-3 hours post feeding in young, healthy subjects $[17,36])$ triggers an increase in superoxide which then manifests in an increase in blood $\mathrm{H}_{2} \mathrm{O}_{2}$. Following this rise in $\mathrm{H}_{2} \mathrm{O}_{2}$, lipids undergo oxidation which then leads to the delayed appearance of MDA which can be detected in the circulation. In the present study, MDA was still increasing at the end of the collection period, highlighting the delayed response for this marker of lipid peroxidation, which often occurs between 4-6 hours post feeding. Our failure to extend the collection time beyond three hours may be considered an additional limitation of this work.

The present study is the fourth in which we have shown strong, positive correlations between the TAG response to feeding and the oxidative stress response to feeding [16-18]. Because the measurement of serum TAG is relatively simplistic and cost effective, if oral lipid tolerance tests were considered for inclusion within a clinical setting, the simple measurement of TAG may allow for the prediction of blood oxidative stress biomarkers. Future investigations using a large and diverse subject population may seek to further investigate this relationship and to subsequently develop regression equations which may serve to predict the oxidative stress response to feeding using blood TAG as the primary predictor variable.

In relation to meal size, we did not observe any further increase in either blood glucose or oxidative stress with the $150 \mathrm{~g}$ vs. the $75 \mathrm{~g}$ dextrose meal. Therefore, we feel confident that simple sugar in the form of dextrose is rapidly and efficiently processed by young, healthy men. However, based on the present design, we cannot rule out that a ceiling effect occurs with lipid in relation to either blood TAG or oxidative stress. There is clearly a greater response with the higher lipid load, and further study is needed with ingestion of even higher amounts of lipid in order to adequately address 
the question of whether or not a ceiling effect occurs for oxidative stress in response to lipid feedings.

From an applied point of view, we are uncertain that such work will provide practical data. That is, while subjects generally did not have a problem consuming either dextrose meal or the $33 \mathrm{~g}$ lipid meal, the $66 \mathrm{~g}$ lipid meal was challenging for some subjects-in particular for those who do not routinely ingest high fat meals-and would generally not be consumed in isolation without the inclusion of other macronutrients. However, while this amount of dietary lipid ( $66 \mathrm{~g}$ ) can easily be consumed in a mixed meal (whole food or milkshake), it is likely that a similar oxidative stress response may be observed in a non-laboratory based setting where individuals consume high fat, high calorie meals. In a recent study we have compared a pure lipid meal (heavy whipping cream) to an isocaloric mixed meal of lipid, carbohydrate, and protein, noting a much greater oxidative stress response for the pure lipid meal [18]. However, due to the isocaloric nature of the feeding, the total amount of lipid consumed in the mixed meal was less than that of the pure lipid meal. While the isolated lipid and dextrose meals were necessary to address the questions in the present design, we admit that they may not have much application to individuals consuming mixed meals in a free living environment. Therefore, this should be considered in future designs. Although, bearing in mind that the total amount of dietary energy is relatively low even when including the $66 \mathrm{~g}$ lipid meal $(600$ kcal), adding carbohydrate and protein to the lipid load allows for greater practical application, and would likely contribute to a similar or greater oxidative stress response as observed in the present study $[16,38,39]$. Such a possibility highlights the need to minimize the intake of saturated fat for the purpose of health maintenance.

\section{Conclusion}

The present findings indicate that minimal oxidative stress is observed following ingestion of dextrose at either $75 \mathrm{~g}$ or $150 \mathrm{~g}$, or lipid at $33 \mathrm{~g}$. Moreover, lipid ingestion at $66 \mathrm{~g}$ leads to greater oxidative stress than lipid at $33 \mathrm{~g}$ or dextrose at either $75 \mathrm{~g}$ or $150 \mathrm{~g}$. Based on these data we conclude that in a sample of young and healthy men, only $66 \mathrm{~g}$ of lipid (consumed in the form of heavy whipping cream) leads to a significant increase in blood oxidative stress. Future research should consider the inclusion of older and metabolically compromised individuals, in an effort to determine their response to such feedings. These studies should consider the incorporation of a more realistic "mixed meal" in terms of macronutrient composition. This should provide for practical applications that may have clinical relevance pertaining to oxidative stress specific ill-health and disease.

\section{Acknowledgements}

The authors thank the subjects for their willingness to participate in this work.

\section{Authors' contributions}

RJB was responsible for the study design, biochemical work, statistical analyses, and manuscript preparation; REC, MMK, KEM, and TMF were responsible for data collection, blood collection and processing, and assistance with manuscript preparation. All authors read and approved of the final manuscript.

\section{Competing interests}

Financial support for this work was provided by the University of Memphis. The authors declare no competing interests.

Received: 2 July 2010 Accepted: 27 July 2010 Published: 27 July 2010

\section{References}

1. Halliwell B, Cross CE: Oxygen-derived species: their relation to human disease and environmental stress. Environ Health Perspect 1994, 102(Suppl 10):5-12.

2. Schafer $F Q$, Buettner GR: Redox environment of the cell as viewed through the redox state of the glutathione disulfide/glutathione couple. Free Radic Biol Med 2001, 30(11):1191-1212.

3. Hancock JT: The role of redox mechanisms in cell signalling. $\mathrm{Mol}$ Biotechnol 2009, 43(2):162-166.

4. Chung HY, Cesari M, Anton S, Marzetti E, Giovannini S, Seo AY, Carter C, Yu BP, Leeuwenburgh C: Molecular inflammation: Underpinnings of aging and age-related diseases. Ageing Res Rev 2009, 8(1):18-30.

5. Fisher-Wellman $\mathrm{K}$, Bloomer RJ: Acute exercise and oxidative stress: a 30 year history. Dyn Med 2009, 8:1.

6. Bloomer RJ: Effect of exercise on oxidative stress biomarkers. Adv Clin Chem 2008, 46:1-50.

7. Sies H, Stahl W, Sevanian A: Nutritional, dietary and postprandial oxidative stress. J Nutr 2005, 135(5):969-972.

8. Dalle-Donne I, Rossi R, Colombo R, Giustarini D, Milzani A: Biomarkers of oxidative damage in human disease. Clin Chem 2006, 52(4):601-623.

9. O'Keefe $\mathrm{H}$, Bell DS: Postprandial hyperglycemia/hyperlipidemia (postprandial dysmetabolism) is a cardiovascular risk factor. Am J Cardiol 2007, 100(5):899-904.

10. Nishikawa T, Edelstein D, Du XL, Yamagishi S, Matsumura T, Kaneda Y, Yorek MA, Beebe D, Oates PJ, Hammes HP, Giardino I, Brownlee M: Normalizing mitochondrial superoxide production blocks three pathways of hyperglycaemic damage. Nature 2000, 404(6779):787-790.

11. Brownlee M: The pathobiology of diabetic complications: a unifying mechanism. Diabetes 2005, 54(6):1615-1625.

12. Du X, Edelstein D, Obici S, Higham N, Zou MH, Brownlee M: Insulin resistance reduces arterial prostacyclin synthase and eNOS activities by increasing endothelial fatty acid oxidation. J Clin Invest 2006, 116(4):1071-1080.

13. Zhang J, Johnston G, Stebler B, Keller ET: Hydrogen peroxide activates NFkappaB and the interleukin-6 promoter through NFkappaB-inducing kinase. Antioxid Redox Signal 2001, 3(3):493-504.

14. Monnier L, Mas E, Ginet C, Michel F, Villon L, Cristol JP, Colette C: Activation of oxidative stress by acute glucose fluctuations compared with sustained chronic hyperglycemia in patients with type 2 diabetes. JAMA 2006, 295(14):1681-1687.

15. Bae JH, Bassenge E, Kim KB, Kim YN, Kim KS, Lee HJ, Moon KC, Lee MS, Park KY, Schwemmer M: Postprandial hypertriglyceridemia impairs endothelial function by enhanced oxidant stress. Atherosclerosis 2001, 155(2):517-523.

16. Bloomer RJ, Ferebee DE, Fisher-Wellman KH, Quindry JC, Schilling BK: Postprandial oxidative stress: Influence of sex and exercise training status. Med Sci Sports Exerc 2009, 41(12):2111-2119.

17. Bloomer RJ, Fisher-Wellman KH: Lower postprandial oxidative stress in women compared to men. Gender Medicine .

18. Fisher-Wellman $\mathrm{KH}$, Bloomer RJ: Exacerbated postprandial oxidative stress induced by a lipid meal compared to isoenergetically administered carbohydrate, protein and mixed meals. Am J Clin Nutr

19. Neri S, Signorelli SS, Torrisi B, Pulvirenti D, Mauceri B, Abate G, Ignaccolo L, Bordonaro F, Cilio D, Calvagno S, Leotta C: Effects of antioxidant 
supplementation on postprandial oxidative stress and endothelial dysfunction: a single-blind, 15-day clinical trial in patients with untreated type 2 diabetes, subjects with impaired glucose tolerance, and healthy controls. Clin Ther 2005, 27(11):1764-1773.

20. Tushuizen ME, Nieuwland R, Scheffer PG, Sturk A, Heine RJ, Diamant M: Two consecutive high-fat meals affect endothelial-dependent vasodilation, oxidative stress and cellular microparticles in healthy men. J Thromb Haemost 2006, 4(5):1003-1010.

21. Tsai WC, Li YH, Lin CC, Chao TH, Chen JH: Effects of oxidative stress on endothelial function after a high-fat meal. Clin Sci (Lond) 2004, 106(3):315-319.

22. Ceriello A, Taboga C, Tonutti L, Quagliaro L, Piconi L, Bais B, Da Ros R, Motz E: Evidence for an independent and cumulative effect of postprandial hypertriglyceridemia and hyperglycemia on endothelial dysfunction and oxidative stress generation: effects of short- and longterm simvastatin treatment. Circulation 2002, 106(10):1211-1218.

23. Mohanty P, Ghanim H, Hamouda W, Aljada A, Garg R, Dandona P: Both lipid and protein intakes stimulate increased generation of reactive oxygen species by polymorphonuclear leukocytes and mononuclear cells. Am J Clin Nutr 2002, 75(4):767-772.

24. Anderson RA, Evans ML, Ellis GR, Graham J, Morris K, Jackson SK, Lewis MJ, Rees A, Frenneaux MP: The relationships between post-prandial lipaemia, endothelial function and oxidative stress in healthy individuals and patients with type 2 diabetes. Atherosclerosis 2001, 154(2):475-483.

25. Saxena R, Madhu SV, Shukla R, Prabhu KM, Gambhir JK: Postprandial hypertriglyceridemia and oxidative stress in patients of type 2 diabetes mellitus with macrovascular complications. Clin Chim Acta 2005, 359(12):101-108.

26. Kawano H, Motoyama T, Hirashima O, Hirai N, Miyao Y, Sakamoto T, Kugiyama K, Ogawa H, Yasue H: Hyperglycemia rapidly suppresses flowmediated endothelium-dependent vasodilation of brachial artery. J Am Coll Cardiol 1999, 34(1):146-154.

27. Mohanty P, Hamouda W, Garg R, Aljada A, Ghanim H, Dandona P: Glucose challenge stimulates reactive oxygen species (ROS) generation by leucocytes. J Clin Endocrinol Metab 2000, 85(8):2970-2973.

28. Sampson MJ, Gopaul N, Davies IR, Hughes DA, Carrier MJ: Plasma F2 isoprostanes: direct evidence of increased free radical damage during acute hyperglycemia in type 2 diabetes. Diabetes Care 2002, 25(3):537-541

29. Serin O, Konukoglu D, Firtina S, Mavis O: Serum oxidized low density lipoprotein, paraoxonase 1 and lipid peroxidation levels during oral glucose tolerance test. Horm Metab Res 2007, 39(3):207-211.

30. Miyazaki Y, Kawano H, Yoshida T, Miyamoto S, Hokamaki J, Nagayoshi Y, Yamabe H, Nakamura H, Yodoi J, Ogawa H: Pancreatic B-cell function is altered by oxidative stress induced by acute hyperglycaemia. Diabet Med 2007, 24(2):154-160.

31. van Oostrom AJ, Sijmonsma TP, Verseyden C, Jansen EH, de Koning EJ, Rabelink TJ, Castro Cabezas M: Postprandial recruitment of neutrophils may contribute to endothelial dysfunction. J Lipid Res 2003, 44(3):576-583.

32. Schindhelm RK, Alssema M, Scheffer PG, Diamant M, Dekker JM, Barto $R$ Nijpels G, Kostense PJ, Heine RJ, Schalkwijk CG, Teerlink T: Fasting and postprandial glycoxidative and lipoxidative stress are increased in women with type 2 diabetes. Diabetes Care 2007, 30(7):1789-1794.

33. Ceriello A, Bortolotti N, Motz E, Crescentini A, Lizzio S, Russo A, Tonutti L, Taboga C: Meal-generated oxidative stress in type 2 diabetic patients. Diabetes Care 1998, 21(9):1529-1533

34. Ceriello A, Quagliaro L, Catone B, Pascon R, Piazzola M, Bais B, Marra G, Tonutti L, Taboga C, Motz E: Role of hyperglycemia in nitrotyrosine postprandial generation. Diabetes Care 2002, 25(8):1439-1443.

35. Fisher-Wellman $\mathrm{KH}$, Bloomer RJ: A high calorie dextrose or maltodextrin meal does not increase postprandial oxidative stress in healthy young men. Int I Sport Nutr Exerc Metab

36. Bloomer RJ, Fisher-Wellman KH, Bell HK: The effect of long-term, highvolume aerobic exercise training on postprandial lipemia and oxidative stress. Phys Sportsmed 2010, 38(1):64-71.

37. Bell HK, Bloomer RJ: Impact of serum estradiol on postprandial lipemia, oxidative stress, and inflammation across a single menstrual cycle. Gend Med 2010, 7(2):166-178.

38. Melton CE, Tucker PS, Fisher-Wellman KH, Bloomer RJ: Acute exercise does not attenuate postprandial oxidative stress in pre-diabetic women. The Physician and Sportsmedicine 2009, 36(2):1-10.
39. Bloomer RJ, Cole BJ, Fisher-Wellman KH: Racial differences in postprandial oxidative stress with and without acute exercise. Int I Sport Nutr Exerc Metab 2009, 19(5):457-472.

40. Jentzsch AM, Bachmann H, Furst P, Biesalski HK: Improved analysis of malondialdehyde in human body fluids. Free Radic Biol Med 1996, 20(2):251-256.

41. Dhindsa S, Tripathy D, Mohanty P, Ghanim H, Syed T, Aljada A, Dandona P: Differential effects of glucose and alcohol on reactive oxygen species generation and intranuclear nuclear factor-kappaB in mononuclear cells. Metabolism 2004, 53(3):330-334.

42. Mc Clean CM, Mc Laughlin J, Burke G, Murphy MH, Trinick T, Duly E, Davison GW: The effect of acute aerobic exercise on pulse wave velocity and oxidative stress following postprandial hypertriglyceridemia in healthy men. Eur J Appl Physiol 2007, 100(2):225-234.

43. Pruessner JC, Kirschbaum C, Meinlschmid G, Hellhammer DH: Two formulas for computation of the area under the curve represent measures of total hormone concentration versus time-dependent change. Psychoneuroendocrinology 2003, 28(7):916-931.

44. Zhu W, Zhong C, Yu Y, Li K: Acute effects of hyperglycaemia with and without exercise on endothelial function in healthy young men. Eur $J$ Appl Physiol 2007, 99(6):585-591.

45. Schinkovitz A, Dittrich P, Wascher TC: Effects of a high-fat meal on resistance vessel reactivity and on indicators of oxidative stress in healthy volunteers. Clin Physiol 2001, 21(4):404-410.

46. Liu Y, Fiskum G, Schubert D: Generation of reactive oxygen species by the mitochondrial electron transport chain. J Neurochem 2002, 80(5):780-787.

47. Sul HS: Metabolism of Fatty Acids, Acylglycerols, and Sphingolipids. Biochemical, Physiological, \& Molecular Aspects of Human Nutrition St. Louis, Missouri: ElsevierStipanuk MH , Second 2006, 449-449-491.

48. Bae JH, Schwemmer M, Lee IK, Lee HJ, Park KR, Kim KY, Bassenge E: Postprandial hypertriglyceridemia-induced endothelial dysfunction in healthy subjects is independent of lipid oxidation. Int I Cardiol 2003, 87(2-3):259-267.

49. Fisher-Wellman K, Bloomer RJ: Macronutrient specific postprandial oxidative stress: Relevance to the development of insulin resistance. Curr Diabetes Rev 2009, 5(4):228-238.

doi:10.1186/1476-511X-9-79

Cite this article as: Bloomer et al:: Postprandial oxidative stress in response to dextrose and lipid meals of differing size. Lipids in Health and Disease 2010 9:79.

\section{Submit your next manuscript to BioMed Central and take full advantage of:}

- Convenient online submission

- Thorough peer review

- No space constraints or color figure charges

- Immediate publication on acceptance

- Inclusion in PubMed, CAS, Scopus and Google Scholar

- Research which is freely available for redistribution

Submit your manuscript at www.biomedcentral.com/submit
C Biomed Central 